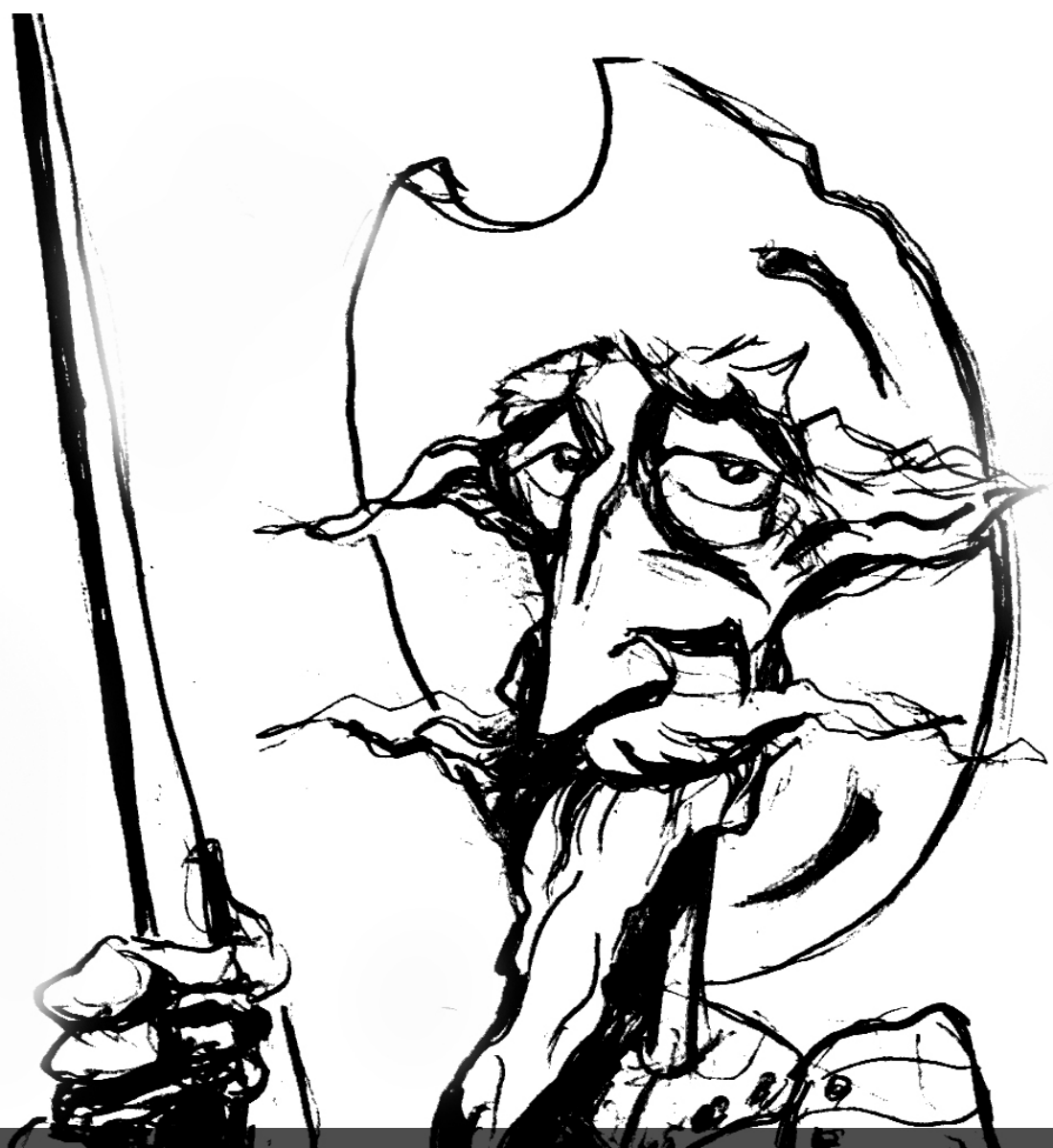

La organización del territorio: los interventores y el Consejo Superior Peronista, 1947-1955.

[Nicolás Quiroga] 


\section{La organización del territorio: los interventores y el Consejo Superior Peronista, 1947-1955*} The Organization of Territory: Inspectors and the Consejo Superior Peronista,
1947-1955

NicolÁs QUiROGA

\section{Resumen}

El artículo reconstruye la nómina de interventores del Partido Peronista, nombrados por el Consejo Superior Peronista entre 1947 y 1955, para discutir las relaciones entre un rol reconocido en el peronismo y las formas de organizar al partido en todo el territorio. Aspira a intervenir en la conceptualización de la noción de "trayectoria política" y propone atender a la importancia de las convenciones partidarias para pensar el modo en que el peronismo construyó su organización en el largo plazo.

\section{Palabras clave}

Partidos políticos - peronismo - trayectoria política - organización - territorio

\begin{abstract}
This article develops a database of inspectors of Consejo Superior del Partido Peronista to discuss relations between a recognized role in Peronism (interventores) and the territorial organization of Peronist Party. With the concept of "political career" it aims to think about the importance of party conventions to analyze how Peronism built his organization in the long term.
\end{abstract}

\section{Key words}

Political Parties - Peronism - political career territorial organization

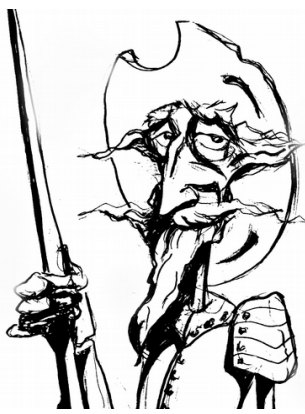

Recibido con pedido de publicación el 20 de enero de 2017

Aceptado para su publicación el 15 de marzo de 2017

Versión definitiva recibida el 22 de abril de 2017

Nicolás Quiroga, Universidad Nacional de Mar del Plata, Consejo Nacional de Investigaciones Científicas y Técnicas, Argentina, e-mail: nfquirog@gmail.com

\footnotetext{
* Una versión preliminar de este artículo fue expuesta en el Panel de discusión: "Escalas y trayectorias políticas en los estudios sobre el primer peronismo", Mar del Plata, 26 de abril de 2012. Agradezco por los comentarios a María del Mar Solís Carnicer, así como a los evaluadores de la revista.
}

Esta obra se publica bajo licencia Creative Commons. Atribución-NoComercial-CompartirIgual Internacional

Quiroga, Nicolás "La organización del territorio: los interventores y el Consejo Superior Peronista, 1947-1955", Prohistoria, Año XX, núm. 27, jun. 2017, pp. 55-77.

\section{Introducción}

Uno de los aspectos revisitados en las últimas décadas para investigar sobre el primer peronismo ha sido el partido político. La organización del peronismo ha 
sido investigada a través del análisis de los dos partidos políticos que definieron a las fuerzas que inicialmente apoyaron a Perón en las elecciones de 1946: el Partido Peronista y el Partido Peronista Femenino. ${ }^{1}$ Hacia fines de los años noventa y principios del 2000, las preguntas que alentaron la investigación sobre la organización política del peronismo estuvieron orientadas a revisar ideas firmemente instaladas sobre la autoridad de Perón como explicación última de las prácticas políticas de los dirigentes y simpatizantes peronistas, y condujeron a nuevas preguntas sobre las prácticas políticas, los conflictos situados, las segundas líneas, entre otras cuestiones que se mantienen en la agenda historiográfica de la historia política desde aquel entonces. A la luz de productivos enfoques sobre las diferencias entre el peronismo en Capital Federal y el peronismo en el interior del país, una larga lista de investigaciones sobre los peronismos provinciales y peronismos a nivel local interpretaron la variable regional. ${ }^{2}$ La historia política definida por esos ejes está "marcada" por luces y sombras que se derivan de los enfoques elegidos. ${ }^{3}$ En lo que respecta a los alcances de las fuentes analizadas puede decirse que: a mayor uso de fuentes de nivel local y enfoques de escala local, menor es la posibilidad de que concibamos las prácticas políticas como "determinadas" o "inyectadas" por instituciones supralocales. Son mayoría los estudios que entienden como fundamentos de la acción, las estrategias e intereses de grupos particulares en el marco de pugnas por "controlar la incertidumbre" (por decirlo en el código muy aceptado- de Angelo Panebianco); mientras que, a mayor uso de documentos de nivel provincial y escala meso, es mayor la posibilidad de que enfaticemos el carácter monolítico de la unidad "provincia" y revisemos con más interés los enfrentamientos entre poderes nacionales y subnacionales. Ha sido, con todo, el más productivo de los enfoques, en tanto fue capaz de instalar una serie de interrogantes que se testearon en distintas geografías, y en la medida en que el enfoque de nivel nacional y documentación de agencias más importantes en la pirámide organizativa lograron relativizar el carácter "omnímodo" de los organismos centrales, y expusieron tensiones allí donde la historiografía tradicional supuso absoluta verticalidad. ${ }^{4}$ Podría decirse que estos últimos enfoques a los que hago referencia no contrapesaron la fuerza de la perspectiva provincial, con (contrarios) acentos "nacionales".

\footnotetext{
${ }^{1}$ MACKINNON, Moira Los años formativos del Partido Peronista (1946-1950), Instituto Di TellaSiglo Veintiuno, Buenos Aires, 2002; BARRY, Carolina Evita capitana. El Partido Peronista Femenino, 1949-1955, Universidad Nacional de Tres de Febrero, Caseros, 2009.

${ }^{2}$ La escala provincial puede seguirse en las compilaciones de MACOR, Darío - TCACH, César (eds.) La invención del peronismo en el interior del país, Universidad Nacional del Litoral, Santa Fe, 2003; MACOR, Darío; TCACH, César (eds.) La invención del peronismo en el interior del país II, Universidad Nacional del Litoral, Santa Fe, 2013; AELO, Oscar H. (comp.) Las configuraciones provinciales del peronismo: actores y prácticas políticas, 1945-1955, Instituto Cultural de la Provincia de Buenos Aires, La Plata, 2010. La escala local en MARCILESE, José El peronismo en Bahía Blanca. De la génesis a la hegemonía 1945-1955, Editorial UNS, 2015; CAMAÑO SEMPRINI, Rebeca Peronismo y poder municipal. De los orígenes al gobierno en Río Cuarto (Córdoba, 1943-1955), Prohistoria, Rosario, 2014; QUIROGA, Nicolás "La dimensión local del Partido Peronista. Las unidades básicas durante el primer peronismo, Mar del Plata, 1946-1955", Tesis de doctorado, UNMdP, 2010, entre otras investigaciones.

${ }^{3}$ QUIROGA, Nicolás "De la inexistencia a la ubicuidad. El partido peronista en la historiografía académica", en ACHA, Omar y QUIROGA, Nicolás El hecho maldito. Conversaciones para otra historia del peronismo, Prohistoria, Rosario, 2012.

${ }^{4}$ MACKINNON, Moira Los años formativos..., cit.; PROL, Mercedes Estado, movimiento y Partido Peronista. La ingeniería institucional en Santa Fe, 1943-1955, Siglo Veintiuno, Buenos Aires, 2012.
} 
Por otro lado, si agregamos la variable "ideológica" a este mapa imaginado de los estudios sobre la organización del Partido Peronista, el panorama es todavía más complejo. No hay correlaciones fuertes entre escalas, tipos de fuentes y concepciones sobre el Partido Peronista. En algunas investigaciones de nivel local el peronismo ha sido concebido como refractario de prácticas democráticas, ${ }^{5}$ en otras del mismo nivel se lo ha pensado como faccioso en el sentido productivo del término, sin utilizar el término "democrático" para definirlo. ${ }^{6}$ Lo mismo puede decirse de las investigaciones en el cauce provincial: el mendocino como resultado inestable de múltiples procesos políticos locales, ${ }^{7}$ el bonaerense como plataforma de una facción nacional, ${ }^{8}$ el salteño como "cesarismo", 9 el santafesino y el cordobés de distintos ángulos sin resultados concurrentes pero marcadamente conflictivo y poblado de elementos reaccionarios; ${ }^{10}$ el tucumano como cada vez más verticalista y autoritario. ${ }^{11}$ Por otra parte, análisis electorales que cruzan fuentes legislativas y procesos electorales o legislación y conflicto político se inclinan por consideraciones casi contrapuestas con respecto al peronismo. ${ }^{12}$

El primer peronismo, si alguna significación en firme ha ganado en las investigaciones de historia política, tiene menos que ver con una forma particular de acción política y mucho más con un contexto histórico en el que las prácticas políticas de grupos, organizaciones y dirigencias identificadas como peronistas comienzan a definir tópicos, asuntos, que por su recurrencia posterior, podríamos pensar como partes originarias del horizonte de expectativas del peronismo a lo largo de su historia. Sin embargo, y pese a que no puede explicarlo todo, la reconstrucción de sus instituciones principales resulta fundamental para comprender un proyecto político de incontables agrupamientos locales y poderosas fuerzas centrípetas, enmallados en conflictos propios de un proceso intenso de movilización social. Acaso una de las más notables y menos analizadas es el Consejo Superior Peronismo (CSP). ${ }^{13}$ En este

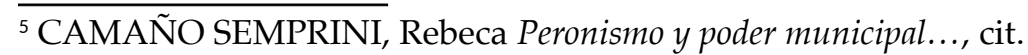

${ }^{6}$ QUIROGA, Nicolás "La dimensión local del Partido Peronista...", cit.

7 GARZÓN ROGÉ, Mariana El peronismo en la primera hora. Mendoza, 1943-1946, EDIUNC, Mendoza, 2014.

8 AELO, Oscar El peronismo en la provincia de Buenos Aires 1946-1955, Eduntref, Buenos Aires, 2012.

9 CORREA, Rubén y QUINTANA, Sergio "Las agencias del poder: intervenciones partidarias y formación del Partido Peronista en Salta, 1949-1952", en TCACH, César y MACOR, Darío La invención del peronismo en el interior del país II, cit.

10 TCACH, César Sabattinismo y Peronismo. Partidos políticos en Córdoba, 1943-1955, Sudamericana, Buenos Aires, 1991; MACOR, Darío "La construcción de una hegemonía electoral, Santa Fe, 1946-1955", en TCACH, César y MACOR, Darío La invención del peronismo en el interior del país II, cit.; PROL, Mercedes Estado, movimiento y Partido Peronista..., cit.

${ }^{11}$ RUBINSTEIN, Gustavo "La 'llave del norte'. El partido peronista: hegemonía política y conflictos internos, 1946-1955", en GUTIÉRREZ, Florencia y RUBINSTEIN, Gustavo (comps.) El primer peronismo en Tucumán. Nuevos avances y perspectivas, EDUNT, Tucumán, 2012.

${ }^{12}$ SABATO, Hilda - TERNAVASIO, Marcela - DE PRIVITELLIO, Luciano y PERSELLO, Ana Virginia Historia de las Elecciones en la Argentina. 1805 -2011, El Ateneo, Buenos Aires, 2011; PROL, María Mercedes Estado, movimiento y Partido Peronista..., cit.

${ }^{13}$ Hasta ahora fue posible reconstruir y analizar parte de su funcionamiento a la luz de fuentes históricas indirectas. Recientemente, el Archivo Rojas dispuso para la consulta pública las Actas de Resoluciones del Partido Consejo Superior Peronista. Departamento de Estudios Históricos Navales, Fondo Isaac Francisco Rojas. El Libro de resoluciones del Consejo Superior Ejecutivo del Partido Peronista (en adelante CSP, Libro de resoluciones) son 4 libros foliados que registran las 
artículo analizaremos las actas de resoluciones de ese organismo para evaluar la importancia de uno de los roles más persistentes en la historia del peronismo: el de interventor. El término es amplio y remite a distintas funciones de un espectro que va desde la función de promoción y organización, a funciones relacionadas con la puesta en orden y el disciplinamiento en un territorio determinado. Este es un texto que se funda en una reconstrucción nominal pero que busca avanzar en una definición de la noción de "trayectoria política" que incorpore, en la imaginada carrera de dirigentes políticos, saberes no tan fácilmente cuantificables.

El análisis de las actas de resoluciones se ajusta en el cuadrante de las fuentes y enfoques "nacionales". Contribuye a perfilar una institución sobre la que se ha escrito con documentos secundarios (prensa, sobre todo) o bien con análisis parciales de las actas de resoluciones. ${ }^{14}$ Pero hay que dejar en claro que, así como en la escala local las demandas locales se destacan en los documentos analizados, en las actas de resoluciones del CSP sobresalen las resoluciones tendientes a "ordenar" el variado panorama de las provincias. Y es en ese sentido que deliberadamente no nos detendremos a considerar si el CSP durante el primer peronismo fue "verticalista" o no constituyó sino un fusible en la cadena de mando que tenía a Perón como único artífice. Sostener que estamos frente a una institución con vocación centralizadora y a documentos de control y custodia de un poder supralocal en detrimento de otros locales, no puede ser una conclusión sino el comienzo de la reflexión para comprender el tono de las resoluciones y una de las funciones de esas actas. Poner el foco en las trayectorias políticas relacionadas con el cargo de "interventor", en base a una reconstrucción de las actividades de los interventores partidarios entre 1947 y 1955, nos permitirá ensayar algunas ideas sobre el peronismo toutcourt. Como expondré más adelante, mi perspectiva insiste en moverse a caballo de los enfoques que revisan "carreras políticas" y los enfoques que recuperan la dimensión organizativa para comprender la dinámica partidaria. Dos son los fundamentos de enfocar este artículo en los interventores: por un lado, verificamos que en muy poco tiempo pasan a ser legítimos intermediarios entre el territorio y el CSP, escribiendo un arreglo importante al reglamento partidario de principios de 1947 y adelantando algunas normas definidas con posterioridad en la Carta Orgánica de 1954; y por otro lado, el rol fue ganando espesor y las prácticas de los primeros años fueron inscribiéndose en el cargo. Como un ADN político, una serie de funciones y experticia definieron tácitamente al cargo. De modo que puede seguirse allí una forma de articulación que perduró incluso más que otras instituciones del Partido Peronista (como el propio CSP).

$\mathrm{Si}$, como muchos han indicado, la política es siempre política territorial, entonces este trabajo habla sobre el modo en que las élites peronistas, y sobre todo Perón, intentaron hacer encajar al conjunto de prácticas políticas peronistas (y en ocasiones a todo el resto) en un esquema de partido primero, $y$

resoluciones del CSP desde mediados de 1947 hasta la última reunión del CSP antes del Golpe de Estado de 1955. Según consta en el primer libro, ese material fue entregado al almirante Isaac Rojas en abril de 1963. URL:

http:/ / www.archivosabiertos.com/ centroDeDocumentos.php?documentos=fondoRojas [Última consulta: mayo de 2016].

${ }^{14}$ AELO, Oscar “Carisma, democracia, verticalismo. El Partido Peronista argentino (1947-1955)", mimeo, 2015. 
movimiento posteriormente. Eso significa que tanto el Consejo Superior Peronista como los roles de intervención deben ser entendidos como modos de construir lo que se denominó "unidad" de los peronistas. Puede decirse que esto es común a todos los partidos, a toda la política, y eso no sería un error. Pero independientemente de los contenidos, la modalidad importa. Y en este punto, retener esa idea nos obliga a poner en contexto la lógica de "centralización", de "verticalismo" partidario. Entiendo que, a partir de la lectura del libro de resoluciones del CSP (que no es un libro de actas), ese organismo fue más bien un instrumento con muchas dificultades por hacerse escuchar, que comenzó tratando de decir lo que había que hacer, pasó a escribir todos los nombres de los candidatos y terminó perfeccionado las herramientas disciplinarias. Expulsar afiliados, intervenir provincias y proclamar candidatos fueron sus actividades más importantes, en ese orden de precedencia. Pero luego, después de 1955, esas funciones no necesariamente quedaron adosadas al "espíritu" de la institución. No puedo decir lo que fue el CSP, sino lo que hizo. ¿Será posible tratar de hacer una panorámica del rol del interventor, visto desde esa agencia, que dialogue con distintas investigaciones que han reconstruido algunas de las prácticas concretas de esos actores, en distintas provincias?

Como dije, la razón de este texto entonces es afinar la noción de "trayectoria política" para continuar reflexionando sobre la historia política del peronismo. La hipótesis que propongo, para pensar las reconstrucciones que realizo, es que el concepto de "trayectoria política" implica carreras políticas y militancia política. Se han pensado de modo separado estas dos cuestiones. ${ }^{15}$ Desde el andarivel de la reconstrucción nominal o prosopográfica, a duras penas es posible clasificar o etiquetar aquello relacionado con el ethos militante para ser incorporado en las trayectorias analizadas. Desde aproximaciones etnográficas, no han podido integrar las napas históricas sobre las que se asienta el sentido común de los militantes. La noción más ajustada a esta propuesta es la de trabajo político. Dice Gastañaga, a quien sigo en este apartado:

"Desde el punto de vista de mis interlocutores, el trabajo político especifica un tipo de quehacer político que no sólo se distingue de la militancia sino también del cumplimiento de la función asociada a un cargo político. Si bien requiere apoyarse en la legalidad y legitimidad que brindan las institituciones, para producir obras políticas son también fundamentales otras relaciones sociales basadas en vínculos entre personas que crean compromisos y obligaciones vinculantes. En este sentido, el trabajo político aúna actividades que pueden (y suelen) pasar desapercibidas como trabajo."16

Con dificultad será posible tramitar desde el procesamiento de bases de datos relacionales, la significación contextual -no polisémica- del término "lealtad". Esto ha sido mejor pensado desde distintos enfoques etnográficos. El rol de interventor puede ser un buen lugar para tratar de cruzar investigaciones provenientes de la historiografía sobre carreras políticas, ${ }^{17}$ élites o profesionales

\footnotetext{
${ }^{15}$ Una notable excepción en CUCCHETTI, Humberto Combatientes de Perón, herederos de Cristo. Peronismo, religión secular y organizaciones de cuadros, Prometeo Libros, Buenos Aires, 2010.

${ }^{16}$ GASTAÑAGA, Julieta El trabajo político y sus obras. Una etnografía de tres procesos politicos en la Argentina contemporánea, Antropofagia, Buenos Aires, 2010, p. 319.
} 
de la política e investigaciones sobre militancia política. ${ }^{18}$ La conjetura que propongo es que ese rol pudo haber contribuido a crear trayectorias políticas de "lealtad", "ortodoxas" de "referentes históricos", etc. a raíz de un tipo particular de trabajo político; y la vez contribuyó a diseñar un tipo de trabajo político no siempre rentado, no siempre reglamentado, que fue incorporándose a la "memoria institucional", o bien, podría decirse, pasó a estar a disposición de los militantes. ${ }^{19}$ Es posible que un enfoque de esta naturaleza contribuya a comprender cómo ciertas prácticas se hicieron convenciones y a la vez, los roles organizativos contribuyeron a estilizar conocimientos o "baquías" políticas.

A los efectos de discutir la propuesta, desarrollo en este texto una idea general sobre el CSP -en base a la literatura existente-, luego me detengo en caracterizar el rol de los interventores y exponer particularidades de ese trabajo político durante el primer peronismo, para finalmente presentar brevemente algunas trayectorias políticas.

\section{El Consejo Superior peronista}

El CSP es una institución que aparece en varias ocasiones en la historia del Partido Peronista (en adelante PP). Se creó en enero de 1947 como la agencia más importante en la estructura del nuevo partido. Como tal se mantuvo hasta el Golpe de Estado de 1955. En distintos momentos de los años venideros, el CSP haría esporádicas apariciones con el fin de organizar, ordenar, normalizar la vida partidaria del peronismo. Por momentos incluso rivalizó con otra gran institución partidaria como fue el Comando Superior Peronista, también una pieza mucho más previsible en su constitución durante el primer peronismo que a posteriori. ${ }^{20}$

\footnotetext{
${ }_{17}$ Véase como ejemplo el dossier coordinado por Marcela Ferrari en el número 7 de la revista Polhis, "De políticos y profesionalización de la política", 2011.

18 BALBI, Fernando De leales, desleales y traidores. Valor moral y concepción de política en el peronismo, Antropofagia, Buenos Aires, 2007; ROSATO, Ana “Líderes y candidatos: elecciones internas en un partido político", en ROSATO, Ana y BALBI, Fernando (comps.) Representaciones sociales y procesos politicos, Antropofagia-IDES, Buenos Aires, 2003; SOPRANO, Germán "Doña Silvia. Análisis de redes políticas en el peronismo de la provincia de Misiones durante una campaña electoral municipal", en Andes, núm. 19, 2008; QUIRÓS, Julieta El porqué de los que van. Peronistas y piqueteros en el Gran Buenos Aires (una antropología de la política vivida), Antropofagia, Buenos Aires, 2011.

${ }^{19}$ El término "memoria institucional" es de Oscar Aelo. Entiendo que ese término no puede ser usado para el campo de las prácticas políticas, pero sí para precisar el tipo de cargos que integran la institucionalidad del Partido Peronista. Pero los alcances de esta idea deben ser discutidos. Como Marshall Sahlins sostuvo: las categorías de la acción siempre se ponen en riesgo en la práctica. Por otra parte, como dije antes, no siempre estuvo codificado en los reglamentos partidarios.

${ }_{20}$ "Pienso que es indispensable que el Comando Superior Peronista desaparezca para dejar lugar a la conducción por el Consejo Superior Peronista y todas las dependencias de ese Consejo Superior; a través de los Consejos en las provincias, y en las ramas en que el Movimiento Peronista se articula" dijo Perón durante el Congreso Nacional Justicialista de mayo de 1974. Aunque esa declaración puede explicarse por pugnas políticas del momento, la contraposición nos permite entrever que la segunda forma (CSP) debía integrar instituciones verticales y horizontales, mientras que la primera no los requería necesariamente. PRESIDENCIA DE LA NACIÓN. Secretaría de Prensa y Difusión Perón habla ante el Congreso Nacional Justicialista, Buenos Aires, 1974.
} 
En las investigaciones que indagan sobre el papel de CSP dos enfoques prevalecen: el análisis de su composición, que llamaremos aquí la reconstrucción nominal, y el estudio del rol que le cupo en las pujas internas del peronismo, que denominaremos reconstrucción funcional (Mackinnon, Tcach, Aelo, Melon, Ladeuix, Franco). ${ }^{21}$ La reconstrucción de los antecedentes de los miembros intenta evaluar el estado, en un momento dado, de las fuerzas internas y sus batallas por el control de la incertidumbre. Ese equilibrio inestable en la conformación de una institución fundamental para un partido político (el national council, general secretariat, etc.), es un buen tester para medir el grado de institucionalización de una fuerza política. Mientras tanto, el enfoque discute un presupuesto bastante extendido durante décadas acerca del carácter apendicular del partido en el peronismo, con respecto a sus líderes y al Estado. Algunas de las variables para emplazar la información nominal son: lealtades partidarias de sus miembros (laboristas, renovadores, oficialistas); función legislativa que tenían en el momento de su participación en el CSP (diputados y senadores) ${ }^{22}$; provincia de origen; antigüedad en el CSP; facciones de pertenencia (Mercante; Perón, Eva; "Inciertas"). ${ }^{23}$

Por su parte, la perspectiva que prioriza el análisis funcional del CSP reconstruye las decisiones de esa agencia y el impacto de las mismas en el escenario estudiado. ${ }^{24}$ En esa línea, más ensayada para el primer peronismo, se destacan dos ideas. La que postula que hacia 1950/1951 hubo un cambio drástico en el PP, que se vio reflejado en la composición del CSP y en el tipo de directivas que esta agencia resolvía. Esta idea está bastante extendida, incluso si no resulta relevante en la reconstrucción funcional. Viene a decir que hubo un CSP antes y otro después de esa fecha, en tanto sus funciones cambiaron. Y, por otro lado, la tesitura de que el CSP no fue un "espacio representativo de las 'fuerzas internas' sino, más bien, un espacio peri-carismático: es decir, una instancia de control y centralización en el proceso de toma de decisiones supervisado por el liderazgo carismático de Perón" 25

La distancia entre las conclusiones de la línea de reconstrucción nominal y la de reconstrucción funcional -entre un CSP como condensación de la

\footnotetext{
${ }^{21}$ MACKINNON, Moira Los años formativos del Partido Peronista..., cit.; TCACH, César y MACOR, Darío "El oxímoron peronista en las provincias" en La invención del peronismo en el interior del país II, cit.; AELO, Oscar "Carisma, democracia, verticalismo...", cit.; MELON, Julio César "Normalización partidaria en tiempos de proscripción. El peronismo entre 1963 y 1965" y PROL, Mercedes "El peronismo santafesino y sus divisiones internas. El Partido Obrero de la Revolución, 1946-1955", ambos artículos en MELON, Julio y QUIROGA, Nicolás El peronismo y sus partidos, Prohistoria, Rosario, 2015; LADEUIX, Juan "Perón o muerte en la aldea. Las formas de la violencia política en el interior de la Provincia de Buenos Aires, 1973-1976", Tesis de Doctorado en historia, UNMdP, 2015; FRANCO, Marina "La «depuración» interna del peronismo como parte del proceso de construcción del terror de Estado en la Argentina de la década del 70", en A contracorriente, vol. 8, núm. 3, 2011.

${ }^{22}$ Menos precisa que el resto, esta clasificación no puede extenderse más allá de los primeros años porque además de los recambios de personas, hubo una decisión del CSP de evitar las superposiciones de cargos entre los miembros.

${ }^{23}$ MACKINNON, Moira Los años formativos...cit., pp. 135 y ss.

${ }^{24}$ Marina Franco y Juan Ladeuix analizan el CSP (o el Consejo Superior del Movimiento Justicialista de 1971) en los años setenta. Por su parte, Julio Melon lo hace para los años 60, momento en el que el CSP era una herramienta muy próxima a Perón. Oscar Aelo se detiene en la reconstrucción de las facciones, en especial, la del ascenso de mercantistas al CSP, pero persigue la revisión de la función organizativa del CSP durante el primer peronismo.

${ }_{25} \mathrm{TCACH}$, César "El oxímoron peronista en las provincias", cit., p. 39.
} 
dinámica partidaria durante el primer peronismo y un CSP como instrumento cada vez más afinado de centralización- se hace más pronunciada por la escala elegida. Mientras el análisis de Mackinnon tiene como punto focal al CSP, el de César Tcach es uno de tipo meso y le permite observar las prácticas políticas de los interventores. ${ }^{26}$ Otras investigaciones en clave provincial han llegado a conclusiones similares en lo que concierne al papel jugado por el CSP en la consolidación del régimen peronista. ${ }^{27}$

Estas dos vertientes dibujadas aquí también muestran una tensión entre juicios formales y de valor. En el caso de la línea de la reconstrucción funcional, no queda claro si se trata de una inclinación en el enfoque (el rol de interventor implica objetivos "centralizadores" y eso hace que consideremos "centralizadores" a los interventores) o de un criterio normativo de los autores sobre cómo deberían ser las relaciones entre agencias partidarias nacionales y subnacionales. Lo mismo podemos conjeturar sobre la reconstrucción nominal: o está propiciada por el tipo de información disponible (cualquier universo discreto puede ser tabulado) o bien insiste en hallar heterogeneidad en la cabeza del partido para discutir una visión prejuiciosa sobre las prácticas políticas del peronismo.

Para poder continuar ese debate en sordina, conviene recordar aquí que otro corte en el análisis está dado por la evaluación de las distintas apariciones del CSP a lo largo del tiempo. No hay que olvidar que las "tradiciones", las afinidades o los orígenes ideológicos o militantes de sus miembros fueron haciéndose más relativos para cualquier comprensión del lugar del CSP en la organización general del PP, en la medida que un número limitado de funciones fueron definiéndose como parte de la soberanía del CSP, independientemente de quiénes lo constituyeron. ${ }^{28}$ ¿Fueron esas funciones características comunes a los distintos peronismos? ¿Tuvieron los interventores del peronismo -en tanto

\footnotetext{
${ }^{26}$ Dos aclaraciones. Mackinnon también puede analizar el comportamiento de los interventores. Las caracterizaciones de algunos de los más conocidos (José Emilio Visca, BetinoOttonello, Carlos M. Seeber) son agudas, e igualmente convincente resulta la reconstrucción de la actuación de Alcides Montiel como interventor en Tucumán (MACKINNON, Moira "El protagonismo del movimiento obrero tucumano en la formación del Partido Peronista (19451950)", en GREZ TOSO, Sergio - ZAPATA, Francisco y MACKINNON, Moira Formas tempranas de organización obrera, La Crujía, Buenos Aires, 2003). Pero considera que el rol del interventor está sujeto a distintas variables propias de la temperatura política en la provincia de llegada. La otra aclaración: en el texto de Aelo hay una lectura del CSP desde la investigación que realizó sobre la provincia de Buenos Aires. Su tesis de que el mercantismo fue una facción que intentó darle una coloratura democrática al CSP hace que la escala siga siendo del tipo meso, aun si analiza algunos de los documentos propios del CSP.

${ }^{27}$ CORREA, Rubén y QUINTANA, Sergio "Las agencias del poder: intervenciones partidarias y formación del Partido Peronista en Salta, 1949-1952", en TCACH, César y MACOR, Darío La invención del peronismo... cit.; y GUTIÉRREZ, Florencia y RUBINSTEIN, Gustavo "La permanente búsqueda del orden y la unidad. Formación y trayectoria del peronismo tucumano, 1946-1955", en AELO, Oscar Las configuraciones provinciales del peronismo: actores y prácticas políticas, 19451955, Archivo Levene, La Plata, 2010.

${ }^{28}$ Para S. Levitsky, el concepto institucionalización tiene que ser "desempacado" (infusión de valores, por un lado; rutinización de comportamientos, por el otro), a diferencia de lo que Angelo Panebianco propone en su libro Modelos de Partido, un texto muy relevante en los estudios sobre el PP durante el primer peronismo. En cuanto al CSP, podríamos decir que con el tiempo se cargó de objetivos propios de la organización, apagando los objetivos o intereses personales o de facción. LEVITSKY, Steven "Institutionalization and Peronism: The Case, the Concept, and the Case for Unpacking the Concept", en Party Politics, 1998, vol. 4, núm. 1.
} 
elementos del CSP- el mismo papel tanto a mediados del siglo XX como a principios del siglo XXI?

Entre 1947 y 1955 el CSP soportó muchos cambios. Pasó de tener 10 integrantes en 1947 a tener 7 en 1955; en 1949 comenzó a diseñar roles específicos para algunos de sus miembros (secretarías) hasta asignarles a cada uno de los integrantes, en 1955, un rol organizativo y un control regional (ver tablas 1a, 1b, 1c).

Tabla 1a: Composición del CSP entre enero de 1947 y febrero de 1951

\begin{tabular}{|l|l|l|}
\hline 1947 & 1949 & 1951 (feb) \\
\hline Teisaire, Alberto (presidente) & Teisaire, Alberto (presidente) & Teisaire, Alberto (presidente) \\
\hline Figueiras, Demetrio & Garaguso, Bernardino (Sec. Gral) & Cámpora, Héctor (Sec. Gral) \\
\hline Montiel, Alcides & Goizueta, Mario (Sec. Organización) & Miel Asquía, Ángel José (Sec. Organización) \\
\hline Cruz, Luis & Scatamacchia, Mauricio (Sec. Finanzas) & Giavarini, Alejandro (Sec. Finanzas) \\
\hline Busquet, Alfredo & Viviani, Rinaldo & Viviani, Rinaldo (vocal y trib disciplina) \\
\hline Luco, Francisco & Atala, Luis & Atala, Luis (sec de informaciones) \\
\hline Garaguso, Bernardino & Giavarini, Alejandro & Goizueta, Mario (vocal y ¿trib disciplina?) \\
\hline Bustos Fierro, Raúl & Seeber, Carlos & Seeber, Carlos (vocal y trib disciplina) \\
\hline Borlenghi, Emilio & Miel Asquía, Ángel & Garaguso, Bernardino (vocal y trib disciplina) \\
\hline Cámpora, Héctor & Cámpora, Héctor & Scatamacchia, Mauricio (vocal y trib disciplina) \\
\hline
\end{tabular}

Fuente: MACKINNON, Moira Los años formativos...; AELO, Oscar “Carisma, democracia, verticalismo..." y CSP, Libro de resoluciones.

En 1951 sobrevinieron muchos cambios y el panorama recién se hizo más estable al año siguiente. En marzo de 1951, renuncia Mauricio Scatamacchia e ingresa Abel Montes (más tarde electo diputado nacional por Santa Fe en las elecciones de ese año); en junio renuncia Mario Goizueta y se producen dos trueques: Giavarini pasa a Secretario General (en lugar de H. Cámpora) y Rinaldo Viviani pasa a ejercer el cargo de Secretario de Finanzas que ocupaba Giavarini. En agosto de ese año, Carlos Seeber y Bernardino Garaguso son expulsados del PP y recién en febrero de 1952 quedan cubiertos sus puestos, en un CSP con 7 miembros. En ese equipo, Viviani ya no está y fue reemplazado por Guillermo de Prisco. En mayo de 1953 renuncian Cámpora y Giavarini y entran Alberto Durand y Ramón Albariño. Para ese momento, cada integrante tiene una función: Albariño será el encargado hasta septiembre de 1955 de la Secretaría de Disciplina y Abel Montes de la de Inspecciones (más tarde en manos de Francisco Picallo). ${ }^{29}$ En 1955, el CSP tendrá cambios más notables, incluyendo el reemplazo de su presidente Alberto Teisaire por Alejandro Leloir.

\footnotetext{
${ }^{29}$ La Secretaría de Disciplina tuvo un arreglo en 1954: la creación del Tribunal de Disciplina, con Albariño como presidente y primero con Antonio Grazia, Eduardo Scandone y Bernardo Gago como vocales y más tarde, también en 1954, con Miguel Ángel Di Sarli, José Armando Seco Villalba y Magin Adolfo Roca ocupando el lugar de los tres vocales.
} 
Tabla 1b: Composición del CSP entre febrero de 1952 y mayo de 1953

\begin{tabular}{|l|l|}
\hline 1952 (feb) & 1953 (mayo) \\
\hline Teisaire, Alberto (Presidente) & Teisaire, Alberto (Presidente) \\
\hline Giavarini, Alejandro (Sec. Gral.) & Miel Asquía, Ángel José (Sec. Gral) \\
\hline Cámpora, Héctor (Sec. Organización) & Atala, Luis (Sec. Organización) \\
\hline De Prisco, Guillermo (Sec. Finanzas) & De Prisco, Guillermo (Sec. Finanzas) \\
\hline Miel Asquía, Ángel José (Sec Información) & Durand, Alberto (Sec. Información) \\
\hline Atala, Luis (vocal y tribunal de disciplina) & Albariño, Ramón (Sec. Disciplina General) \\
\hline Montes, Abel (vocal y tribunal de disciplina) & Montes, Abel (Sec. de Inspecciones) \\
\hline Fuente: CSP, Libro de resoluciones, 1952-1955 & \\
\hline
\end{tabular}

TABLA 1C: COMPOSICIÓN DEL CSP EN AGOSTO DE 1955

\begin{tabular}{|l|l|l|}
\hline 1955 (agosto) & \\
\hline Leloir, Alejandro (presidente) & Zona a cargo & Secretaría \\
\hline & Litoral & disciplina \\
\hline Blbariño, Ramón & Buenos Aires & organización \\
\hline Bocalandro, Carlos & Sur & finanzas \\
\hline Fernández, Benito & Cuyo & inspecciones \\
\hline Picallo, Faustino & Centro & informaciones \\
\hline Urrutia, José Miguel & Norte & general \\
\hline San Millán, Ricardo & \\
\hline
\end{tabular}

Fuente: CSP, Libro de resoluciones, 1955

El reglamento partidario de 1947 imaginó un Consejo Superior Ejecutivo como uno de los órganos principales del PP. Debía estar conformado por 24 miembros provenientes de las provincias, Capital Federal y los Territorios, designados por los Consejos Partidarios respectivos. La primera disposición transitoria de esa Carta Orgánica consistió en autorizar al "actual" Consejo Superior como la autoridad máxima, desactivando el modo de elección de sus miembros hasta tanto se pongan en funcionamiento las instituciones previstas en el reglamento. ${ }^{30}$

La Carta Orgánica de 1954 -reglamento que ponía en papel lo que venía haciéndose en la práctica- ya definía al CSP como tal y determinaba que sus miembros debían ser designados por el Jefe Supremo del Partido o por una, imaginada, Junta Consultiva. El CSP en ese documento era "el Comando Estratégico del Partido". ${ }^{31}$

Entre uno y otro reglamento lo que cambia es el modo de circulación de hombres e información. ¿Cómo podía el CSP disponer de esos recursos para operar sobre la dinámica partidaria si sus hombres no traían mandatos locales, es decir, no eran elegidos por los afiliados o por congresos o asambleas generales? La figura que fue ganando terreno en la práctica y que terminó definido como uno de los elementos más importantes de partido fue el interventor. ${ }^{32}$

30 PRESIDENCIA DE LA NACIÓN, Subsecretaría de Informaciones y Prensa. “Carta Orgánica Nacional" [de 1947], en Doctrina Peronista, 1951.

${ }^{31}$ PARTIDO PERONISTA “Carta Orgánica”, en Manual del Peronista, Buenos Aires, 1954, pp. 326416. 


\section{Los interventores}

Como dijimos, nuestro objetivo es precisar el lugar de los interventores durante el primer peronismo para luego avanzar hacia un concepto de "trayectoria política" que nos permita poner a prueba dos ideas: una que supone que algunos de esos dirigentes políticos que operaron como interventores terminarán insuflados de ese expertise, de modo que en distintos períodos posteriores serán convocados desde el PP para poner en práctica esas formas de acción política aprendidas durante los años que van de 1947 a 1955 . Y la otra que propone que esos saberes fueron características de una institución que se originó en los primeros años, cambió de sentido muy tempranamente y con el tiempo estableció sus capacidades. Creemos que durante el primer peronismo fue hegemónico el proyecto que buscaba forjar un partido político orientado al adoctrinamiento y cada vez más lejos de la práctica "comiteril". Ese proyecto no se extendió más allá de 1955 pero el ejercicio de normalizar, pacificar y unificar fue consolidándose como un saber hacer, que a la vez definió un tipo particular de trabajo político: el del interventor.

Una primera indicación sobre los interventores: no siempre se les encargaba ordenar o limpiar un territorio. En numerosas ocasiones el interventor debe organizar o colaborar en la organización local. Esa función ya era importante en los comienzos. No era extraño en 1947 que los mismos integrantes del CSP fueran interventores, además de poseer cargos parlamentarios (ver tabla 2).

TABLA 2: INTERVENCIONES DE LOS MIEMBROS DEL CSP DE 1947-1949

\begin{tabular}{|l|l|}
\hline Miembro del CSP de 1947-1949 & Interventor \\
\hline Montiel, Alcides & Tucumán \\
\hline Cruz, Luis & San Juan y Catamarca \\
\hline Figueiras, Demetrio & Entre Ríos \\
\hline Luco, Francisco & La Rioja \\
\hline Garaguso, Bernardino & Buenos Aires \\
\hline Bustos Fierro, Raúl & San Juan \\
\hline Borlenghi, Emilio & San Luis y Territorios del Norte y del Sur \\
\hline Cámpora, Héctor & Capital Federal \\
\hline Fuente: CSP, Libro de resoluciones & \\
\hline
\end{tabular}

Esa situación cambió en los años siguientes. En el CSP de 1949-1951, solo cumplieron funciones de interventores Rinaldo Viviani (Salta); Alejandro Giavarini (Mendoza); Carlos Seeber (Córdoba) y Luis Atala (San Luis), mientras que en las siguientes composiciones del CSP, solo Guillermo de Prisco fue interventor en La Rioja, durante 1954. Pero subrayemos esto: en los orígenes, la intervención implicaba una agencia organizadora, incluso cuando esto consistiera en políticas centralizadoras. Ese tipo de agencia estuvo, además, bastante extendida en todos los niveles organizativos. En el CSP incluso hubo designaciones con términos más específicos que indicaran ese rol en el mandato: Antonio J. Benítez fue "comisionado" de fines de 1947 hasta abril de 1948 en los Territorios Nacionales de Misiones, Chaco y Formosa; Roberto Cursack fue "Delegado Organizador" en los Territorios Nacionales del Norte y Sur, entre octubre de 1948 y junio de 1949, y luego cumplió el mismo rol solo

\footnotetext{
${ }^{32}$ Nos detenemos en ese tipo de función, pero hubo otros roles como Apoderado General; Secretario Privado; Adscripto; Intendente; Oficial de Enlace y distintas Asesorías.
} 
para los Territorios Nacionales de La Pampa, Neuquén, Río Negro, Chubut y Santa Cruz entre junio de 1949 y mayo de 1951. Fue Oscar Bidegain quien hizo de "Delegado Organizador" en el resto de los Territorios (Misiones, Chaco y Formosa) en ese mismo período. Finalmente, Oscar Albrieu fue también "Delegado Organizador" en Mendoza durante casi todo el año 1950.

Pero desde 1948, junto con medidas tendientes a controlar la agitada actividad política interna, ${ }^{33}$ el CSP comenzó a definir con precisión la figura del interventor y el perfil que paulatinamente fue dibujándose estuvo más cerca de uno del tipo "ojos y oídos del rey" que de uno que actuara en representación de las agencias infrapartidarias. En septiembre de 1948, el CSP resuelve "escuchar" precandidatos sugeridos por los interventores y autorizar a estos a impartir justicia partidaria (suspender afiliados). Más adelante, en junio de 1949, el CSP resolvió sobre las competencias de los interventores partidarios. El espíritu de esta resolución estuvo en sintonía con lo que años más tarde quedará escrito en la Carta Orgánica de 1954. Pese a lo que se ha dicho sobre las pugnas por el control del CSP entre democrático/sindicalistas y carismáticos/políticos, o en otra versión, por el ascenso de una facción "mercantista", las resoluciones del CSP poseyeron desde muy temprano un tinte centralizador que recargaba la figura del interventor por sobre otras formas de gobierno partidario provincial imaginadas o existentes, más allá de los objetivos de facciones o individuales. En la resolución que comentamos, los interventores "representan la autoridad máxima del partido en el distrito que se designen y reemplazan a todos los organismos superiores estatuidos" y tienen dos funciones: adoctrinamiento y organización. En este último apartado se instruía a los interventores acerca del nombramiento de delegados interventores locales y del cuidado necesario al hacerlo para no "herir susceptibilidades". ${ }^{34}$

En resoluciones de años siguientes, esa figura será dada por supuesta. Por ejemplo, cuando en 1950, el CSP caracteriza a las "Juntas de Organización", las hace depender del Interventor de Distrito, ya sin referencia alguna a reglamentos vigentes. ${ }^{35}$ En 1954, al justificar la modificación del reglamento principal del PP, el CSP indicó la necesidad de "suprimir los congresos partidarios, hasta ahora no elegidos, porque representan excesos de soberanía, dando lugar a la formación de prácticamente 25 partidos peronistas, unidos entre sí en forma muy discutible" y en otro punto: "eliminar los comandos con comandantes, origen de la formación de círculos políticos, sectarismos, personalismos, contubernios, trenzas, caudillaje, y demás causas de disociación. Aplicar en cambio, lo establecido en la práctica, la existencia de comandos sin comandante." 36

Los interventores partidarios constituyeron un haz poco diferenciado de cargos del mismo tipo. Además de "Interventor partidario", hay que mencionar "Comisionado"; "Delegado Organizador"; "Inspector General", "Delegado del

\footnotetext{
${ }^{33}$ En febrero de 1948, el CSP resolvió prohibir el uso del término "Peronista" en los nombres de agrupaciones, líneas internas o unidades básicas; y en noviembre de ese año, prohibió todo tipo de acción proselitista en favor de dirigentes locales por fuera del tiempo de las campañas electorales.

${ }^{34}$ CSP, Libro de resoluciones, Res. 18, 10/06/1949.

${ }^{35}$ CSP, Libro de resoluciones, Res. 74, 07/08/1950.

${ }^{36}$ CSP, Libro de resoluciones, Res. 4, 20/01/1954.
} 
CSP"; "Delegado Investigador"; "Inspector General y Supervisor", "Supervisor"; "Organizador" y "Sumariante". ${ }^{37}$

Durante los primeros meses de 1951 sobrevendrá un cambio importante en las políticas de intervención en las provincias (ver gráfico 1). Además de los cambios en la nómina del CSP y la aparición de la primera resolución ceremonial -esto es, una resolución que invertía abundante energía en celebrar un episodio o persona (en ese caso se trató de un aniversario del 24 de febrero de 1946)-, el máximo organismo resolvió reordenar el cuerpo de interventores y nombrar un conjunto de "Inspectores Generales", especie de contralores del primer equipo (ver tabla 4 ).

\section{Gráfico 1. Línea de tiempo de los interventores designados por el CSP $^{38}$}

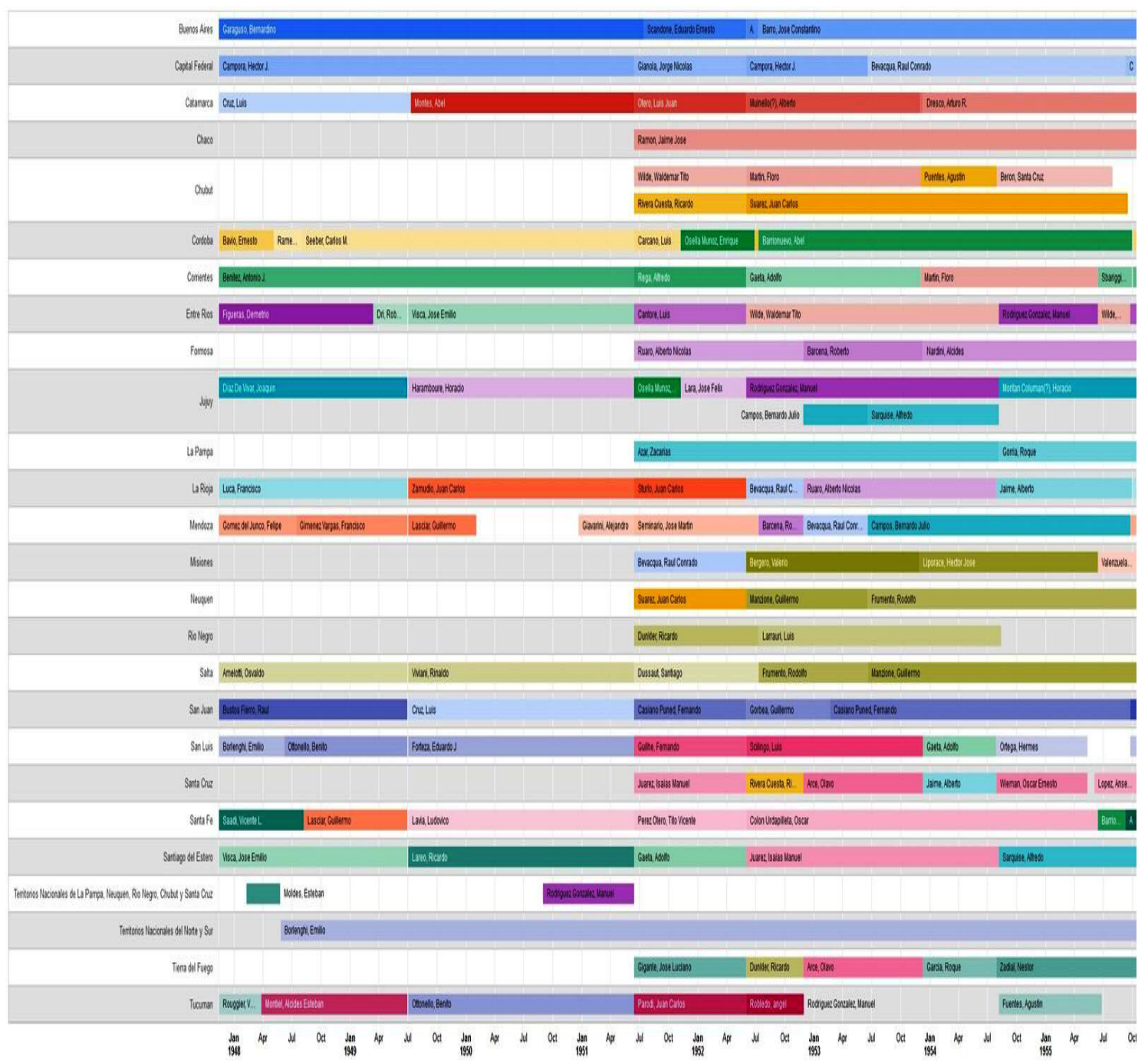

Fuente: CSP, Libro de resoluciones, 1947-1955.

${ }^{37}$ Hubo cuatro "sumariantes": Scatamacchia, Giavarini y Miel Asquía ejercieron ese cargo en Catamarca en los últimos meses de 1949 y Bernardo Gago lo hizo en Entre Ríos, en julio de 1954. ${ }^{38}$ Los gráficos fueron realizados con el Timelines de Google Charts a partir una base de datos relacional. URL: https://developers.google.com/chart/interactive/docs/gallery/timeline [último acceso: febrero de 2016]. 
Tabla 4: “Inspectores generales" e interventores por provincia, en 1951

\begin{tabular}{|c|c|c|}
\hline Zonas & Inspectores Generales & Interventores \\
\hline Capital Federal & Cámpora, Héctor J. & Gianola, Jorge Nicolás \\
\hline Catamarca & Montes, Abel & Otero, Luis Juan \\
\hline Córdoba & Seeber, Carlos M. & Cárcano, Luis \\
\hline Corrientes & Benítez, Antonio J. & Rega, Alfredo \\
\hline Entre Ríos & Visca, José Emilio & Cantore, Luis \\
\hline Jujuy & Haramboure, Horacio & Osella Muñoz, Enrique \\
\hline La Rioja & Zamudio, Juan Carlos & Sturlo, Juan Carlos \\
\hline Mendoza & Díaz, Carlos A. & Seminario, José Martín \\
\hline Salta & Viviani, Rinaldo & Dussaut, Santiago \\
\hline San Juan & Cruz, Luis & Casiano Puñed, Fernando \\
\hline San Luis & Forteza, Eduardo J & Guilhe, Fernando \\
\hline Santa Fe & Lavia, Ludovico & Pérez Otero, Tito Vicente \\
\hline Santiago del Estero & Lareo, Ricardo & Gaeta, Adolfo \\
\hline $\begin{array}{l}\text { Territorios Nacionales de Chubut, Santa Cruz } \\
\text { Tierra del Fuego }\end{array}$ & y Rodríguez González, Manuel & \\
\hline \multicolumn{3}{|c|}{$\begin{array}{l}\text { Territorios Nacionales de La Pampa, Neuquén, Río Cursack, Roberto } \\
\text { Negro y Comodoro Rivadavia }\end{array}$} \\
\hline $\begin{array}{l}\text { Territorios Nacionales de Misiones, Chaco } \\
\text { Formosa }\end{array}$ & y Bidegain, Oscar & \\
\hline Tucumán & Ottonello, Benito & Parodi, Juan Carlos \\
\hline
\end{tabular}

Fuente: CSP, Libro de resoluciones, res. 104, 14/05/1951.

Notas: Las provincias se designan con su nombre actual. El único Interventor General que no fungía como Interventor partidario al momento de la resolución fue Carlos Díaz (en Mendoza estaba Alejandro Giavarini). Algunos de esos Inspectores en los hechos no duraron mucho tiempo en funciones. En 1955 serán designados dos inspectores para Entre Ríos y La Pampa, y un Inspector General, dependiente de la Presidencia del CSP, con salario. Buenos Aires no tuvo Interventor General.

El panorama general en el PP, desde 1949, fue desplazando lo escrito en la Carta Orgánica de 1947 (con excepción de lo ocurrido en Provincia de Buenos Aires) hasta alcanzar una organización de nuevo tipo en 1953 (con elecciones en los niveles más bajos, y Consejos Provinciales designados en algunos lugares, sin convenciones partidarias). Sin embargo, incluso bajo ese formato las intervenciones no desaparecieron completamente. En julio de 1954, en aquellos lugares ya organizados, se dieron de baja las intervenciones, pero se nombró a esos mismos interventores como "Delegados del CSP", con funciones de enlace; asistencia a las reuniones de distrito con voz y sin voto; elevación de informes al CSP; representación del PP en las reuniones de Comandos Tácticos junto con el Secretario Delegado; y la suspensión de cualquier orden de distrito que no se ajuste a las del CSP. ${ }^{39}$

Gracias a la literatura de las últimas dos décadas, conocemos mucho sobre los conflictos provinciales en los que los el CSP por intermedio de los interventores jugó un papel importante. Leídos a partir de los libros de resoluciones del CSP, y entendiendo que el propio organismo tuvo como

${ }^{39}$ CSP, Libros de resoluciones, 06/07/1954. Catamarca, Chubut, Córdoba, Jujuy, La Rioja, Río Negro, Salta, San Juan, San Luis, Santiago del Estero y Tucumán son las provincias que se vieron afectadas. La mayoría de ellas tendrá dos "Delegados del CSP" entre mediados de 1954 y septiembre de 1955. 
objetivo el de liberar de funciones políticas a la mayoría de los agentes partidarios y en especial a los interventores, cuando no reemplazarlos con Consejos, es posible conjeturar que hubo algunas provincias más "problemáticas" que otras. Esa gradación tendría un indicador en el recambio de interventores. Esto no es fácilmente comprobable, en tanto desconocemos las razones de las renuncias de muchos de los hombres enviados a cumplir ese rol. Pero una manera de desarrollar esa hipótesis es revisar la evolución del peronismo en esos lugares (ver gráficos 2; 3 y 4 ).

\section{Gráfico 2. Mapa de provincias con más de 3 intervenciones durante el primer peronismo}

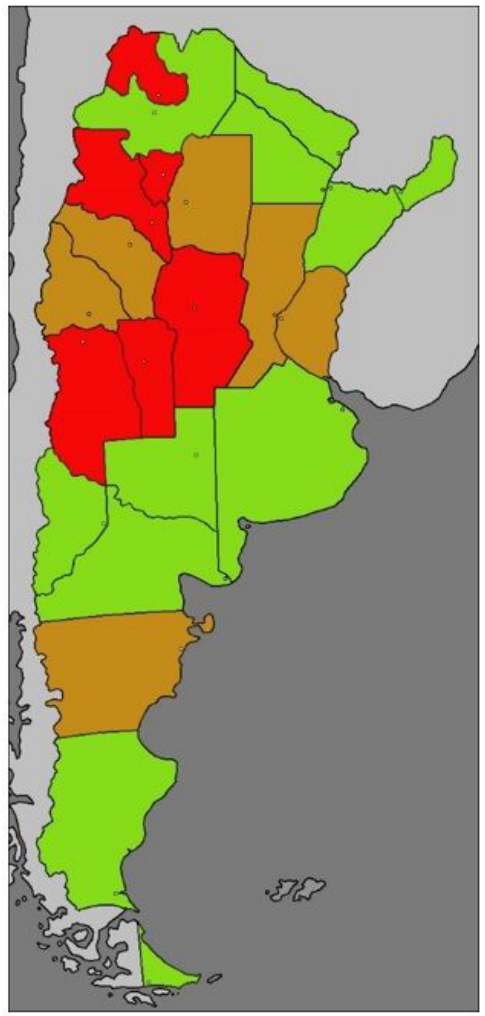

\begin{tabular}{|l|r|}
\hline Provincias & Cantidad de Intervenciones* \\
\hline Mendoza & 11 \\
\hline San Luis & 10 \\
\hline Catamarca & $10^{* *}$ \\
\hline Jujuy & 10 \\
\hline Córdoba & 9 \\
\hline Tucumán & 9 \\
\hline Entre Ríos & 8 \\
\hline La Rioja & 8 \\
\hline Chubut & 8 \\
\hline San Juan & 8 \\
\hline Santa Fe & 7 \\
\hline Sgo. del Estero & 7 \\
\hline Salta & 6 \\
\hline Corrientes & 6 \\
\hline Santa Cruz & 6 \\
\hline Tierra del Fuego & 5 \\
\hline La Pampa & 5 \\
\hline Capital Federal & 4 \\
\hline Buenos Aires & 4 \\
\hline Río Negro & 4 \\
\hline Misiones & 4 \\
\hline * Incluye todos los cargos de tipo intervención. \\
\hline ** 3 sumariantes & \\
\hline
\end{tabular}

Referencias:
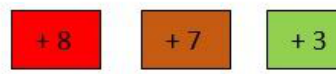

Fuente: elaboración propia a partir de CSP, Libro de resoluciones. 
Gráfico 3: Líneas de tiempo de intervenciones en Catamarca, San Luis, Mendoza y Jujuy, 1947-1955

Catamarca

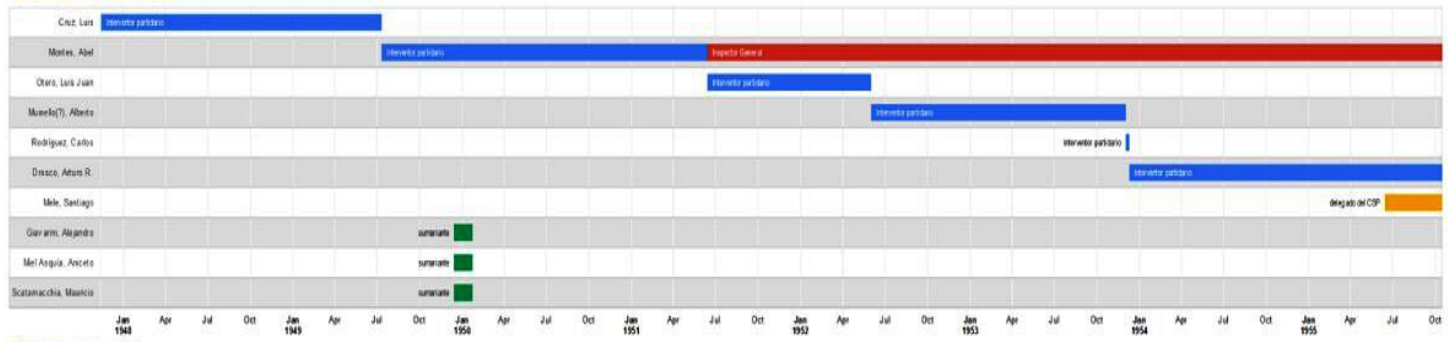

San Luis

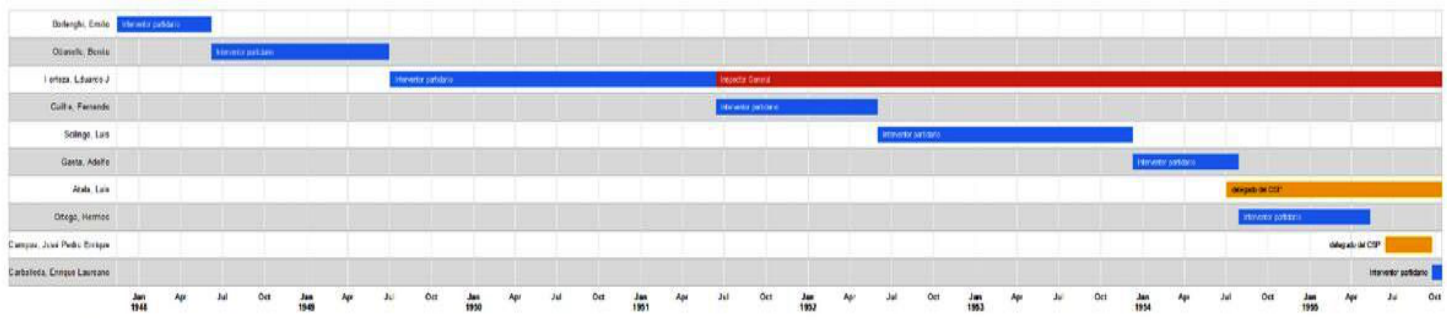

Mendoza

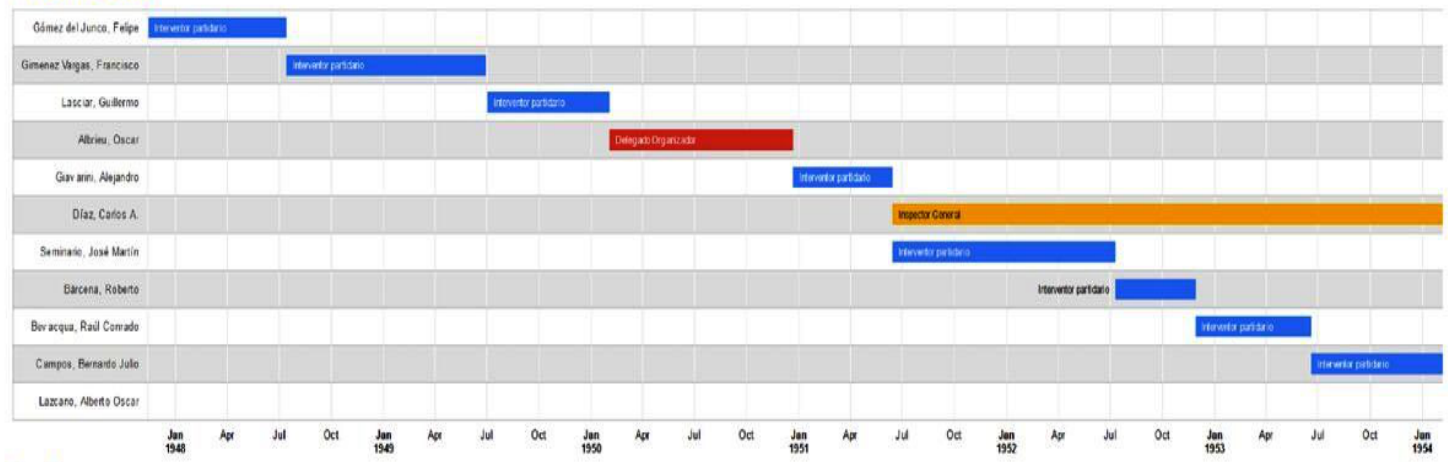

Jujuy

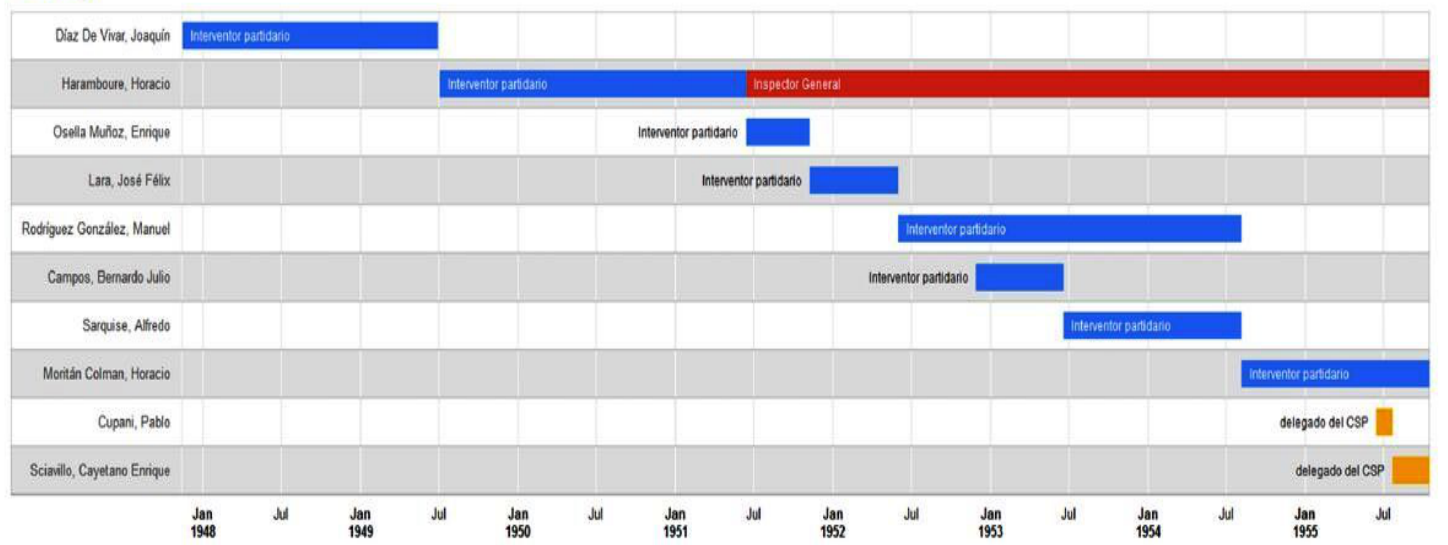

Fuente: elaboración propia a partir de CSP, Libro de resoluciones.

Si no tomamos en cuenta en nuestras consideraciones a los sumariantes que en 1949 fueron enviados a Catamarca para resolver un conflicto de nivel 
provincial, ${ }^{40}$ lo que nos queda bajo una mirada impresionista es que la mayoría de las provincias tuvo conflictos y en ellas los interventores jugaron distintos papeles. Esto se condice con la estrategia del CSP de hacer de los interventores los organismos principales en el orden provincial. Pero también nos dice algo que la historiografía actual no puede procesar porque identifica a los interventores a partir de un conflicto: que, así como podían lograr controlar un problema, podían también provocarlos (el caso menos estudiado y más llamativo fue tal vez la intervención de José Visca en Entre Ríos). El CSP debía ajustar cuentas entonces con los propios enviados. Lo hará sobre todo a partir de la supervisión del "Delegado Inspector". Así sucedió en Santiago del Estero con Isaías Manuel Juárez, con Ruaro en La Rioja, con Luis Larrauri en Río Negro. En San Luis, Adolfo Gaeta será "trasladado a un Territorio Nacional", por no haber actuado duramente contra otro Interventor, Luis Scilingo, a quien más tarde se lo expulsa y se le pide que devuelva la medalla peronista. La misma suerte corrieron Roberto Bárcena por su paso por Formosa, y Olavo Arce en Santa Fe, pero ya alejado de sus funciones como interventor (en Santa Cruz y en Tierra del Fuego). ${ }^{41}$ En 1955, el CSP expulsa a otro interventor en San Luis (Hermes Ortega) y a uno de Santa Cruz (Oscar Wieman). ${ }^{42}$ Aunque no podemos reconstruir la toma de decisiones a partir del libro de resoluciones del CSP, el circuito implicaba personal en provincia (tribunal de disciplina e interventores $\mathrm{O}$ Inspectores) y al Tribunal de Disciplina del propio CSP, institución que fue acaparando paulatinamente las páginas del libro de resoluciones. En definitiva: los conflictos provinciales no pueden ser considerados el fundamento del rol de los interventores.

Gráfico 4: Líneas de tiempo de provincias con menos intervenciones, 19471955

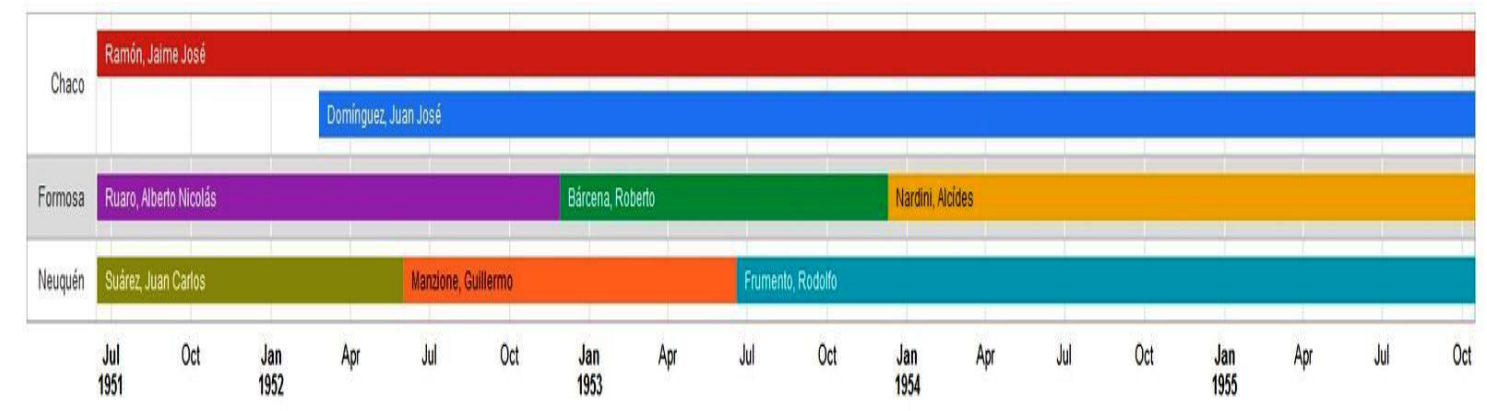

Fuente: elaboración propia a partir de CSP, Libro de resoluciones.

\section{Las trayectorias}

Las trayectorias políticas de los interventores es una idea a explorar. Las carreras políticas no pueden definirse por la experiencia acumulada en un cargo, sino que son líneas que pueden trazarse desde una punta a la otra del esquema institucional de un partido político, más allá de este y más allá

\footnotetext{
40 El pedido de intervención provino de la delegada censista del PPF catamarqueño. Rápidamente fueron expulsados Vicente Leónidas Saadi, Benjamín Juárez y Raúl Madueño. CSP, Libro de resoluciones, Res. 35, 20/11/1949.

${ }^{41}$ CSP, Libros de resoluciones, distintas resoluciones con fecha 13/07/1954. En La Rioja, además, se inicia un sumario al secretario de la intervención. Las resoluciones contra Scilingo y contra Arce tienen fecha 07/12/1954.

${ }^{42}$ CSP, Libros de resoluciones, res. 62, 12/04/1955.
} 
también del sistema político. Pero las trayectorias políticas de los interventores, como las trayectorias políticas de los intelectuales, poseen un sesgo en este caso técnico que las convierte en un andarivel sobre el cual es posible "hacer carrera" sin "saltar" a otras arenas partidarias.

Uso la palabra "técnico" pero no la opongo a "intelectual" sino a rudimentario o improvisado. Los interventores, si la conjetura que seguimos en este texto es demostrable, acabaron poseyendo "técnicas" para construir consenso y "unidad", o para erradicar focos de conflicto. ${ }^{43}$ La exploración sobre ese tipo de saber, específico pero "bajo", es decir, no fácil de expresar formalmente, tal vez nos permita avanzar en la reflexión sobre convenciones tácitas en el "hacer política" en el peronismo (no porque los interventores supieran verdaderamente qué es lo que había o no que hacer, sino porque acumularon un sentido común partidario, pero que también se ponía en riesgo toda vez que debían actuar como interventores). En la jerga política, el sentido más primordial del término "referente" indicaría este tipo de relación entre un hombre o mujer y un territorio o conocimiento. De todos modos, hay que distinguir en este supuesto dos posibles líneas a explorar: una centrada en las personas (carreras políticas) y la otra centrada en la institución (desarrollo institucional). La propuesta es avanzar entre esos carriles, identificando y reconstruyendo carreras políticas para perfilar el rol de los interventores en el PP. Será difícil hallar patrones que asocien nombres a ese rol en distintos momentos del peronismo (por ejemplo, Manuel Rodríguez González o Mauricio Scatamacchia, ambos dirigentes convocados para el mismo trabajo en los años setenta) y más fácil mapear capitales políticos de dirigentes (Osella Muñoz, Héctor Cámpora). La hipótesis más arriesgada es pensar en el rol del interventor como la articulación institucional de un partido político que por momentos batalla por organizarse, por momentos no puede hacerlo, por momentos puede, pero no quiere hacerlo.

De todos modos, consideremos el gráfico 5 que muestra aquellas personas que más veces actuaron como interventores partidarios en este mismo período, para considerar solo aquellas carreras políticas de quienes, suponemos, fueron convocados en repetidas ocasiones porque conocían el territorio y porque eran buenos haciendo lo que hacían.

\footnotetext{
${ }^{43}$ Un ejemplo que seguiremos en otro texto es el de Benito Agulleiro, interventor de nivel bajo, comisionado en Mar del Plata, interventor de conflictos sindicales en Tucumán y Bahía Blanca. En 1943 publica Técnica de la infiltración comunista. Ese conocimiento, más tarde templado en el campo, se hace abstracto, se hace menos silvestre y sirve para otros infiltrados, para otros problemas.
} 
Gráfico 5: Líneas de tiempo de dirigentes con más actuaciones como interventores, 1947-1955. Tabla con datos.

\section{Manuel Rodriguez Gonzalez}

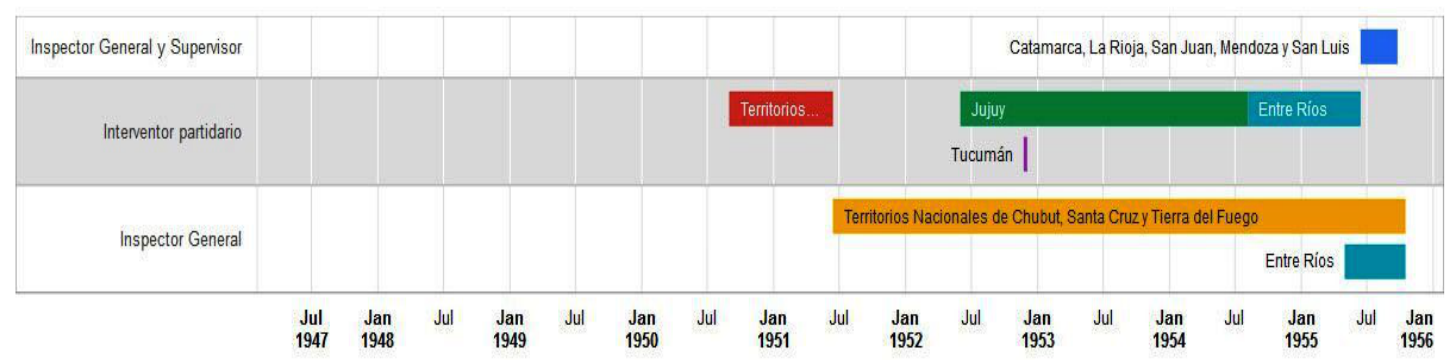

Waldemar Tito Wilde

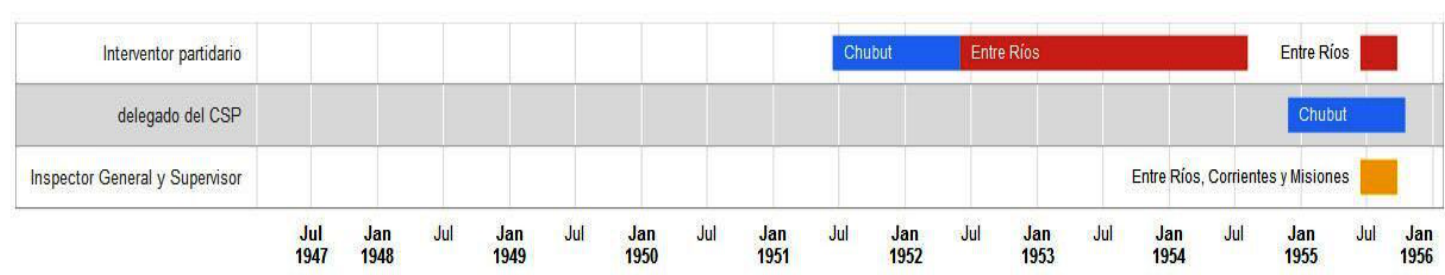

Bevacqua, Raul Conrado

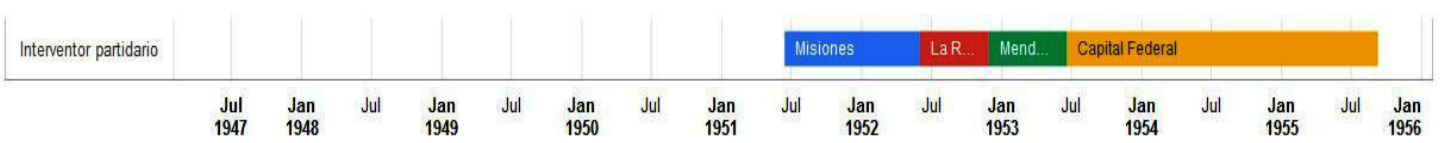

Gaeta, Adolfo

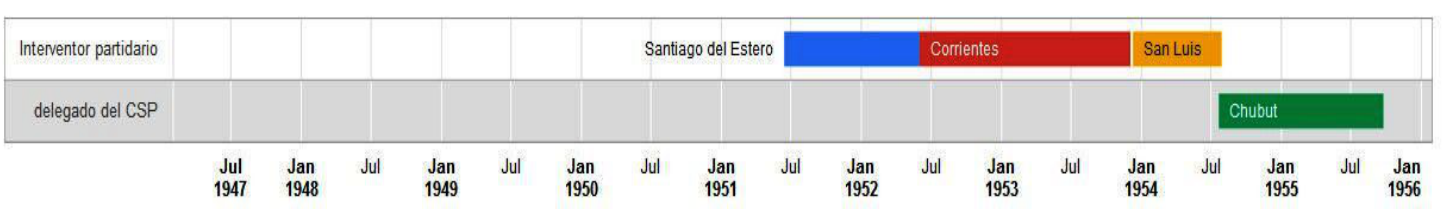

Ottonello, Benito

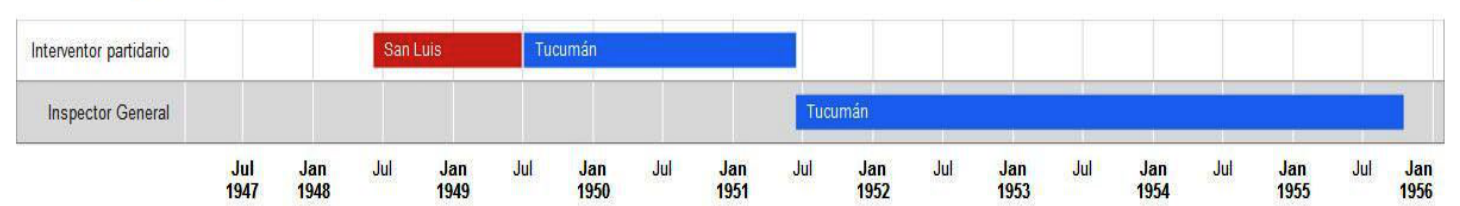

\section{Data:}

\begin{tabular}{|c|c|c|c|c|}
\hline \multicolumn{5}{|c|}{ Rodríguez González, Manuel } \\
\hline $\begin{array}{ll}\text { Inspector } & \text { General } \\
\text { Supervisor } & \end{array}$ & $\mathrm{y}$ & $\begin{array}{l}\text { Catamarca, La Rioja, San Juan, Mendoza y } \\
\text { San Luis }\end{array}$ & $1955,5,14$ & $1955,8,24$ \\
\hline Interventor partidario & & $\begin{array}{l}\text { Territorios Nacionales de La Pampa, } \\
\text { Neuquén, Río Negro, Chubut y Santa } \\
\text { Cruz }\end{array}$ & $1950,7,31$ & $1951,5,14$ \\
\hline Inspector General & & $\begin{array}{l}\text { Territorios Nacionales de Chubut, Santa } \\
\text { Cruz y Tierra del Fuego }\end{array}$ & $1951,5,14$ & $1955,9,16$ \\
\hline Interventor partidario & & Jujuy & $1952,5,1$ & $1954,7,6$ \\
\hline Interventor partidario & & Tucumán & $1952,10,28$ & $1952,10,28$ \\
\hline Interventor partidario & & Entre Ríos & $1954,7,6$ & $1955,5,14$ \\
\hline
\end{tabular}




\begin{tabular}{|c|c|c|c|}
\hline Inspector General & Entre Ríos & $1955,4,1$ & $1955,9,16$ \\
\hline \multicolumn{4}{|l|}{ Wilde, Waldemar Tito } \\
\hline Interventor partidario & Chubut & $1951,5,14$ & $1952,5,1$ \\
\hline Interventor partidario & Entre Ríos & $1952,5,1$ & $1954,7,6$ \\
\hline delegado del CSP & Chubut & $1954,10,26$ & $1955,9,16$ \\
\hline $\begin{array}{lll}\text { Inspector } & \text { General } & \text { y } \\
\text { Supervisor } & & \end{array}$ & Entre Ríos, Corrientes y Misiones & $1955,5,14$ & $1955,8,24$ \\
\hline Interventor partidario & Entre Ríos & $1955,5,14$ & $1955,8,24$ \\
\hline \multicolumn{4}{|l|}{ Bevacqua, Raúl Conrado } \\
\hline Interventor partidario & Misiones & $1951,5,14$ & $1952,5,1$ \\
\hline Interventor partidario & La Rioja & $1952,5,1$ & $1952,10,28$ \\
\hline Interventor partidario & Capital Federal & $1953,5,19$ & $1955,8,9^{*}$ \\
\hline Interventor partidario & Mendoza & $1952,10,28$ & $1953,5,19$ \\
\hline \multicolumn{4}{|l|}{ Gaeta, Adolfo } \\
\hline Interventor partidario & Santiago del Estero & $1951,5,14$ & $1952,5,1$ \\
\hline Interventor partidario & Corrientes & $1952,5,1$ & $1953,11,3$ \\
\hline Interventor partidario & San Luis & $1953,11,10$ & $1954,6,29$ \\
\hline delegado del CSP & Chubut & $1954,6,22$ & $1955,8,24$ \\
\hline \multicolumn{4}{|l|}{ Ottonello, Benito } \\
\hline Interventor partidario & Tucumán & $1949,5,30$ & $1951,5,14$ \\
\hline Inspector General & Tucumán & $1951,5,14$ & $1955,9,16$ \\
\hline Interventor partidario & San Luis & $1948,5,7$ & $1949,5,30$ \\
\hline
\end{tabular}

* Bevacqua probablemente no se mantuvo como interventor de Capital Federal luego de asumir como Ministro de Asistencia Social y Salud Pública, en reemplazo de Ramón Carrillo. Aparentemente fue Juan Carlos Lorenzo quien lo relevó en condición de interino, hasta que en agosto de 1955 asumiera John William Cooke. En la resolución de nombramiento de Cooke figura Lorenzo como interino y no hay resolución de renuncia de Bevacqua.

Fuente: elaboración propia a partir de CSP, Libro de resoluciones.

Incluí el cargo de "Inspector General" (1951) porque funcionó como valoración de los servicios prestados por los interventores. Aunque apenas hubo pocos casos de interventores con desaprobación explícita de sus servicios, el hecho de que las personas no hayan vuelto a ser convocada puede resultar un ponderador que nos indique un desempeño no esperado. Si no consideramos ese cargo como relevante en esta línea de aproximación, Benito Ottonello quedaría fuera de la tabla porque, como interventor, solo pasó de San Luis a Tucumán.

Diferentes son los otros casos, por varios motivos, además de serlo por el número de veces que fueron convocados. Fueron interventores en el ciclo 19511955. Algunos de ellos tuvieron que trabajar en la misma provincia (Rodríguez González y Wilde en Entre Ríos; Wilde y Gaeta en Chubut).

Rodríguez González previamente fue diputado por la provincia de Buenos Aires (el parlamento fue una cantera importante para el reclutamiento de interventores), y tuvo también participación en la vida partidaria del 
peronismo bonaerense. ${ }^{44}$ En su tarea como interventor, según las investigaciones del peronismo en las distintas provincias por las que pasó, Rodríguez González fue un interventor "apostólico", uno de los que llevó dos mandatos básicos para el orden provincial: adoctrinamiento y organización partidaria. En 1953 prometió en Tucumán un orden ascendente para esa organización (elegir autoridades de básicas, luego de distritos y luego provinciales). ${ }^{45} \mathrm{Un}$ año antes, en septiembre de 1952 había finiquitado el mismo proceso en Jujuy. ${ }^{46}$ No puedo saber si la superposición de cargos relacionados con la organización partidaria significó funciones concretas en los Territorios del Sur o en las provincias cuyanas. ${ }^{47}$ Tampoco hay datos sobre su gestión en Entre Ríos. Aunque en 1955, el CSP lo advierte severamente por no aplicar con rigor las directivas indicadas el año anterior contra un afiliado interventor, al que se promete procesar, como señalé más arriba. ${ }^{48}$ En mayo será relevado de ese puesto, aunque no sabemos si fue por esa razón. De todos modos, en agosto de 1955, pasó a ser adscripto al CSP, sin función concreta hasta nuevo aviso. ${ }^{49}$ En 1974 formará parte de la legión de interventores designados por Perón para atender los conflictos provinciales. $^{50}$

Waldemar Tito Wilde fue, como Bevacqua, médico. En 1948 estaba asignado a Servicios Sanitarios de Correos y Telecomunicaciones y, al menos en 1954 se desempeñaba como titular de la primera cátedra de Fisiología Humana de la UBA. ${ }^{51}$ Desde 1952 estuvo asignado a Entre Ríos y a Chubut. En ningún caso sabemos sobre su desempeño.

Sobre el desempeño de Bevacqua como interventor no tenemos referencias. Murió en 1960.

\footnotetext{
${ }^{44}$ Diputado Nacional entre 1946 y 1950. Círculo de Legisladores de la Nación Argentina, URL: http://www.clna.com.ar/institucional/presidencia.php. Provenía del laborismo según AELO, Oscar "Elites políticas en la provincia de Buenos Aires: peronistas y radicales en las elecciones de 1948", en EIAL, vol. 13, núm. 2, 2002. Ambos antecedentes igualmente los registra Benito Ottonello, quien también pasó como interventor por Tucumán. RUBINSTEIN, Gustavo "La 'llave del norte'. El partido peronista: hegemonía política y conflictos internos, 1946-1955", en GUTIÉRREZ, Florencia y RUBINSTEIN, Gustavo (comps.) El primer peronismo en Tucumán. Nuevos avances y perspectivas, EDUNT, Tucumán, 2012.

${ }^{45}$ RUBINSTEIN, Gustavo “La 'llave del norte'...", cit.

46 KINDGARD, Adriana "Estado, partido y elecciones en Jujuy en tiempos del primer peronismo", en AELO, Oscar (comp.) Las configuraciones... cit.

${ }^{47} \mathrm{Su}$ nombre no figura en BONA, Aixa y VILABOA, Juan "El peronismo en los Territorios Nacionales patagónicos. Una aproximación al análisis comparativo", en BONA, Aixa y VILABOA, Juan (coords.) Las formas de la política en la Patagonia. El primer peronismo en los Territorios Nacionales, Biblos, Buenos Aires, 2007. Los autores indican que más relevante para la política local fueron los delegados locales designados, y subrayan la dificultad de reconstruir la trayectoria de dirigentes que llegaban al Sur y volvían a la Capital, sin dejar rastros.

${ }^{48}$ CSP, Libro de resoluciones, res. 23, 1/03/1954.

${ }^{49}$ CSP, Libro de resoluciones, res. 169, 24/08/1955.

${ }^{50}$ KINDGARD, Adriana "La dirigencia peronista jujeña y el movimiento obrero en el tercer gobierno de Perón: del entendimiento a la violencia política”, en Polhis, núm. 6, 2013.

${ }^{51}$ PRESIDENCIA DE LA NACIÓN Boletín Oficial, Abril de 1948, URL:

https://archive.org/stream/Boletin Oficial Republica Argentina 1ra seccion 1948-0416/1948-04-16 djvu.txt y ROMERO, Lucía Ana “Conformación y desarrollo de una tradición de investigación clínica médica: Alfredo Lanari y el Instituto de Investigaciones Médicas (IIM) (1957-1976)", Tesis de doctorado en Ciencias Sociales, FLACSO, 2010.
} 
Diferente es el caso de Adolfo Gaeta. Su activismo está referido en investigaciones sobre Comodoro Rivadavia y sobre Corrientes. ${ }^{52}$ Fue en Corrientes donde tuvo que trabajar más. A Gaeta y al nuevo gobernador, Raúl Castillo, les tocó estar al mando de la reorganización del Partido y el Estado, respectivamente. Después de un año, Gaeta anunció el fin de esa etapa, pero aún le tocaba capear la crisis desencadenada por los incidentes acaecidos durante una visita de Perón. Floro Martín, uno de los interventores más cercano al reorganizado CSP, lo reemplazó a fines de $1953 .^{53}$

\section{Algunas conclusiones}

Las intervenciones partidarias no son las únicas instituciones que merecen ser consideradas a la hora de pensar cómo fue la organización del PP a lo largo de la historia del peronismo. Los interventores de gobierno y los sindicales deberían formar parte de una revisión más amplia del rol de esos cargos en la construcción política. ${ }^{54}$ Es un debate que excede al peronismo y que recupera una larga conversación sobre democracia, república y federalismo. Un ejemplo indica mejor hacia dónde apuntamos: sabemos que Domingo Mercante, mientras duró como Gobernador de la provincia de Buenos Aires intervino más municipios que quien le siguió en su cargo, Carlos Aloé. ${ }^{55}$ Para algunos, el hecho de que Mercante lo hiciera con municipios peronistas y Aloé contra municipios radicales es un indicador que merece ser evaluado a la hora de "medir" democracia, institucionalidad, etc. Para otros investigadores, la extendida existencia de interventores partidarios es un indicador de debilidad democrática, falta de democracia interna, etc. En este artículo subrayamos la importancia de analizar la modalidad de los procesos que tramitan esas tensiones.

Hablando sobre el peronismo en las provincias, Tcach sostuvo:
"Soñó con ser un partido de acero provisto de una rígida disciplina, pero en los hechos fue con frecuencia un semillero de pelitos minúsculos. No hubo Gulag que reflejase esa concepción vertical y organicista de la práctica política, pero distó de carecer de efectos de sentido." 56

Tcach percibe un hilo conductor que se gesta durante el primer peronismo y define de algún modo la historia toda del peronismo en esa tensión entre imaginarse como un partido fuerte y flotar en mareas de faccionalismo. Aunque no coincida con esa tradición que Tcach piensa como cierta, creo que la

\footnotetext{
${ }^{52}$ CARRIZO, Gabriel "Saldando deudas. El peronismo en la Gobernación Militar de Comodoro Rivadavia, 1944-1955", en TCACH, César y MACOR, Darío (eds.) La invención..., cit.; y SOLÍS CARNICER, María del Mar "El peronismo correntino entre el gobierno y la oposición. Tensiones, conflictos y transformaciones tras las elecciones de 1951", ponencia presentada en XIV Jornadas Interescuelas/Departamentos de Historia, Departamento de Historia de la Facultad de Filosofía y Letras, UNCuyo, Mendoza, 2013.

${ }^{53}$ SOLÍS CARNICER, María del Mar "El peronismo correntino...", cit.

${ }^{54}$ Sobre las intervenciones federales a gobernadores peronistas ver SERVETTO, Alicia 73/76 El gobierno peronista contra las "provincias montoneras", Siglo Veintiuno, Buenos Aires, 2010.

${ }_{55}$ MARCILESE, José "Estado provincial y municipios bonaerenses, una relación conflictiva en los años del primer peronismo", en Anuario del Instituto de Historia Argentina, núm. 9, 2009.

56 TCACH, César "Estudios sobre peronismos provinciales: un cambio en el régimen de preguntas", en Estudios Sociales, núm. 46, 2014, p. 241.
} 
tensión entre pleitos y "partido de acero" es muy pertinente para discutir la figura del interventor. En la idea de "semillero de pleitos políticos" hay toda una protodefinición del territorio -aspecto que también Moira Mackinnon entendió como mandatario para entender la organización del PP durante el primer peronismo-. El interventor o delegado del CSP puede haber tenido órdenes de la máxima agencia partidaria, pero operó como vertebrador de dos espacios que se reiteran en abismo en un sistema de clasificación que define la política en general y las prácticas políticas de partidos de masas ([alto/bajo] [centro/periferia] [unidad/facción] [líderes/masas] [adentro/afuera] [formal/informal]). Al mirar procesos importantes en el camino indefinido hacia la unidad partidaria del peronismo (1947, 1952, 1959, 1963, 1972, 1985" 2007, entre otras), la intervención parece proponer una hoja de ruta para acomodar esa tensión de la que hablamos. Durante el primer peronismo, en el PP se sostuvieron por encima de otras, dos tipos de instituciones: las unidades básicas y el CSP; en el medio hubo sobre todo Consejos Provinciales designados e Interventores. Las dirigencias no serían moldeadas, en el esquema que comenzó a imponerse desde 1948 en adelante, por la competencia intrapartidaria, sino a través de la Escuela Superior Peronista, fundada unos años más tarde. La organización a dos puntas (bien "abajo" y bien "arriba") pudo verse en muchos momentos de la historia del peronismo. Con dificultad surgieron, en esos marcos, formas de elección en asambleas o por medio del voto directo para establecer autoridades partidarias de nivel medio. Es por eso tal vez que la figura del interventor mantuvo su prestigio: para cualquiera de las dos puntas de la pirámide organizativa, el interventor podía ofrecer sus servicios: organizar o controlar. Fue, por último, ese saber hacer-que el CSP durante el primer peronismo imaginó vaciado de política "comiteril"- lo que continuamente le devolvió la humanidad a quien encarnaba ese rol, poniéndolo muchas veces del lado de facción.

\footnotetext{
${ }^{57}$ CLOSA, Gabriela "Crisis, renovación partidaria y transformaciones políticas en el peronismo de córdoba, 1983-1987", en Astrolabio, número 4. URL:

http://www.astrolabio.unc.edu.ar/articulos/partidospoliticos/articulos/closa.php
} 